\title{
Decision-Making for Rewilding: An Adaptive Governance Framework for Social-Ecological Complexity
}

\author{
James R. A. Butler ${ }^{1}$, Mariella Marzano ${ }^{2}$, Nathalie Pettorelli ${ }^{3}$, Sarah M. Durant ${ }^{3}$, \\ Johan T. du Toit ${ }^{4}$ and Juliette C. Young ${ }^{5 *}$ \\ ${ }^{1}$ Commonwealth Scientific and Industrial Research Organisation Land and Water, Brisbane, QLD, Australia, ${ }^{2}$ Forest \\ Research, Northern Research Station, Roslin, United Kingdom, ${ }^{3}$ Institute of Zoology, Zoological Society of London, London, \\ United Kingdom, ${ }^{4}$ Department of Wildland Resources, Utah State University, Logan, UT, United States, ${ }^{5}$ Agroécologie, \\ AgroSup Dijon, INRAE, Université Bourgogne, Université Bourgogne Franche-Comté, Dijon, France
}

\section{OPEN ACCESS}

Edited by:

Jenny Anne Glikman,

Instituto de Estudios Sociales

Avanzados (IESA), Spain

Reviewed by:

Carl-Gustaf Thulin,

Swedish University of Agricultural

Sciences, Sweden

L. Jen Shaffer,

University of Maryland, United States

*Correspondence:

Juliette C. Young

juliette.young@inrae.fr

Specialty section:

This article was submitted to

Human-Wildlife Dynamics,

a section of the journal

Frontiers in Conservation Science

Received: 16 March 2021

Accepted: 18 May 2021

Published: 10 June 2021

Citation:

Butler JRA, Marzano M, Pettorelli N Durant SM, du Toit JT and Young JC (2021) Decision-Making for Rewilding: An Adaptive Governance Framework for Social-Ecological Complexity.

Front. Conserv. Sci. 2:681545 doi: 10.3389/fcosc.2021.681545
Rewilding can be defined as the reorganisation or regeneration of wildness in an ecologically degraded landscape with minimal ongoing intervention. While proposals for rewilding are increasingly common, they are frequently controversial and divisive amongst stakeholders. If implemented, rewilding initiatives may alter the socialecological systems within which they are situated and thus generate sudden and unforeseen outcomes. So far, however, much of the discourse on the planning and implementation of rewilding has focused on identifying and mitigating ecological risks. There has been little consideration of how rewilding could alter the human components of the social-ecological systems concerned, nor governance arrangements that can manage these dynamics. This paper addresses this gap by proposing a generic adaptive governance framework tailored to the characteristics of rewilding, based on principles of managing complex social-ecological systems. We integrate two complementary natural resource governance approaches that lend themselves to the contentious and unpredictable characteristics of rewilding. First, adaptive co-management builds stakeholder adaptive capacity through iterative knowledge generation, collaboration and power-sharing, and cross-scale learning networks. Second, social licence to operate establishes trust and transparency between project proponents and communities through new public-private partnerships. The proposed framework includes structural and process elements which incorporate a boundary organisation, a decision-into-practise social learning exercise for planning and design, and participatory evaluation. The latter assesses rewilding outcomes and pre-conditions for the continuation of adaptive governance and conservation conflict resolution.

Keywords: adaptive capacity, adaptive co-management, conflict transformation, conservation conflict, livelihoods, knowledge, social licence to operate, partnership

\section{INTRODUCTION}

Rewilding, defined in this paper as the reorganisation or regeneration of wildness in an ecologically degraded landscape with minimal ongoing intervention, is a novel and rapidly developing conservation concept, with a burgeoning number of initiatives proposed or implemented (Pettorelli et al., 2019) in diverse social and ecological contexts (Butler et al., 2019). Rewilding initiatives can 
be contentious and divisive amongst the multiple stakeholders involved, creating conflicts that can limit its effectiveness. After implementation, rewilding can also generate sudden and unforeseen ecological changes (Corlett, 2016), and hence unexpected benefits and costs for the stakeholders involved (Pettorelli et al., 2018).

Social-ecological systems consist of societal and ecological components in mutual interaction. They are typified by four key characteristics: interlinked scales and components; nonlinear dynamics caused by cross-scale reinforcing feedback loops that amplify interactions; emergence of sudden and unexpected outcomes; and thus irreducible uncertainty (Gallopin, 1991). Plummer and Armitage (2007) suggest that decision-makers must focus on two primary outcomes from the stewardship of social-ecological systems: ecosystem condition and sustainable livelihoods. In terms of rewilding, decision-makers must anticipate that any initiative is, as rewilding implies, likely to alter existing relationships between system components, potentially generating unanticipated ecosystem and livelihood outcomes.

However, there has been little analysis of rewilding from a social-ecological perspective, or consideration of how to manage the stakeholder conflicts and uncertainties that could emerge (Butler et al., 2019; Durant et al., 2019; Drouilly and O'Riain, 2021). Instead, much of the discourse on planning and implementing rewilding has focused on identifying and mitigating ecological risks (e.g., Batson et al., 2015; Robert et al., 2015; Nogués-Bravo et al., 2016). As a result, many rewilding initiatives are undermined by social rather than ecological challenges (Coz and Young, 2020; Drouilly and O'Riain, 2021).

Governance of natural resources can be defined as "the norms, institutions and processes that determine how power and responsibilities over natural resources are exercised, how decisions are taken, and how citizens... participate in and benefit from [their] management" (Campese et al., 2016, p. 1). Adaptive governance is necessary for social-ecological systems due to their dynamic and unpredictable characteristics. In general, it involves flexible, polycentric and self-organising institutions that link across a system's scales, thus allowing suites of coordinated responses to complex challenges at the necessary levels. Two key attributes of adaptive governance are learning networks that promote knowledge generation and exchange amongst stakeholders across scales, and "bridging organisations" or individuals that broker and facilitate these networks (Folke et al., 2005).

Given the experimental nature of rewilding, and its potentially contentious and unpredictable influences on social-ecological system dynamics, we argue that adaptive governance should be central to both its planning and implementation. In this paper we consider rewilding from a social-ecological systems perspective, and in particular the governance models required to steward the inevitable shifts in human-nature relationships. We propose the integration of adaptive co-management (ACM) and social licence to operate (SLO) in a generic governance framework for rewilding initiatives. We explore why and how this approach could form a foundation for more effective planning and management of rewilding initiatives. We believe that the proposed framework could support the implementation of the newly adopted resolution of the International Union for the Conservation of Nature (IUCN) on rewilding, which aims to develop guidelines for rewilding that include assessments of the relative risks and rewards to ecosystems and local communities (IUCN, 2021).

\section{ADAPTIVE CO-MANAGEMENT}

The design of governance approaches for complex socialecological systems is a growing field of research (e.g., Folke et al., 2005; Armitage et al., 2009; Plummer et al., 2017). ACM has recently evolved as an effective refinement of adaptive governance. It combines the iterative co-learning, knowledge generation and problem-solving of adaptive management with the stakeholder collaboration, power-sharing and alternative institutions of co-management (Armitage et al., 2009; Berkes, 2009; Keith et al., 2011). Folke et al. (2002, p. 8) define ACM as "a process by which institutional arrangements and ecological knowledge are tested and revised in a dynamic, ongoing, self-organised process of trial-and-error." ACM is advocated for the stewardship of social-ecological systems because it encourages cross-scale social networks, integration of multiple knowledge types to solve complex and unprecedented problems, and reflexivity through continual evaluation and learning, which together enhance decision-makers' capacity to anticipate uncertainty and respond to shocks (Olsson et al., 2004; Armitage et al., 2009; Fabricius and Cundill, 2014).

While the "what" of ACM is clear, it has been critiqued for the lack of detail on the "how" and limited evidence of clear outcomes (Rist et al., 2013; Fabricius and Cundill, 2014; Plummer et al., 2017). This is understandable because ACM is itself an emergent property of a social-ecological system, often occurring in response to an exogenous shock or resource crisis (e.g., Olsson et al., 2004, 2006; Butler et al., 2008; Plummer, 2009; Cox et al., 2020). Consequently, there is no blueprint for the process and/or outcomes of ACM since each instance will be context-specific and self-organising (Plummer et al., 2012). Nonetheless, ACM can be engineered by creating a structure and process founded on its principles of multi-stakeholder engagement and learning (e.g., Cundill and Fabricius, 2010; Smedstad and Gosnell, 2013; Butler et al., 2016a,b).

Despite the reasonably recent implementation of ACM, there are already examples of this approach successfully mitigating conservation conflict amongst stakeholders, for example regarding dugong hunting (Butler et al., 2012), seal tourism and salmon fisheries (Butler et al., 2015a; Bellanger et al., 2020; Cox et al., 2020) and "hard edges" around protected areas (Plummer et al., 2017). These examples have identified key pre-conditions for the maintenance of conflict resolution, including long-term government support for the process, strong leadership and champions, bridging organisations or individuals, and cross-scale partnerships (Young et al., 2012; Butler et al., 2015a; Cox et al., 2020). These are now being mainstreamed into conservation conflict efforts (e.g., Redpath et al., 2013; Young et al., 2016; Redpath et al., 2017), where the focus is shifting from conflict resolution, which emphasises compromise and jointly 
agreed outcomes, to conflict transformation, which leverages stakeholder concern and engagement in contentious issues to transform systems (Skrimizea et al., 2020).

\section{SOCIAL LICENCE TO OPERATE}

SLO emerged in the 1990s to describe the informal acceptance, approval or trust that a local community extends to a corporate entity or industry developing new operations, with a specific application to mining (Lacey and Lamont, 2014). The concept has since been extended to other industries, such as forestry (Moffat et al., 2016). SLO is useful for governance because it highlights the need for development proponents to acknowledge and address social concerns about a novel proposal and is the starting point for dialogue between stakeholders (Moffat et al., 2016). It also emphasises the need for a relationship based on trust and transparency to be cultivated between the proponents and local communities, and hence ethical governance and social justice (Lacey and Lamont, 2014). SLO implies that an agreement will be reached between a developer and communities which mirrors the "license" granted by government to the developer to undertake operations, with its necessary safeguards (Moffat et al., 2016).

Kendal and Ford (2017) have assessed the relevance of SLO to threatened species programs. Conservation interventions are likely to be more complicated than a development intervention because stakeholders tend to range from local to global and have a greater spectrum of attitudes on environmental issues (Ford and Williams, 2016). Because conservation initiatives are usually government-led and therefore acting in the public rather than the private interest, more complex partnerships are required between the public sector and local stakeholders (Ojha et al., 2016). Regardless, SLO is appropriate for conservation purposes because it emphasises the need for practitioners to develop trusting relationships with local and other participants, to recognise and address the diversity of their views, and to anticipate and address potential conflict through transparent governance processes (Kendal and Ford, 2017).

\section{AN INTEGRATED ADAPTIVE GOVERNANCE FRAMEWORK}

ACM and SLO provide over-lapping and complementary themes that could contribute to the improved adaptive governance of rewilding. ACM provides a specific focus on iterative colearning, knowledge generation, and cross-scale networks. It also highlights the need for leadership and the roles of bridging organisations or individuals to facilitate these processes. SLO emphasises the establishment of trust and transparency between project proponents and communities, and the formation of novel public-private partnerships amongst multiple stakeholders. Common to both approaches are stakeholder partnerships across scales, recognition of the diversity of their views, social justice, equal representation and power-sharing, new institutional arrangements, and conflict resolution aided by these principles.
Our proposed framework for governing rewilding integrates these themes through two elements: structure and process.

\section{Structure}

The core structural element is a facilitation team which acts as a boundary organisation amongst the multiple private and public stakeholders across scales of the system. It should be emphasised that the establishment and maintenance of a facilitation team requires adequate and consistent resourcing, something which is often overlooked by funders (Butler et al., 2016a). The facilitation team identifies and engages stakeholders, organises activities that enable dialogue and consensus-building, brokers knowledge and information, and mediates in conflict. The team must be regarded as independent, credible and trustworthy by all stakeholders (Olsson et al., 2004; Armitage et al., 2009; Cundill and Fabricius, 2010), and act as a conduit between them, creating the learning networks that are critical to harnessing knowledge and generating innovation (Olsson et al., 2004). Hence, team members must be skilled in cross-sectoral communication, mediation, conflict resolution, event organisation and facilitation (Butler et al., 2017). In light of the importance of the facilitation team, the appointment process is crucial, as is the need for a grievance process to allow communities to voice any concerns.

The team's first task is to carry out a stakeholder analysis for the rewilding location and its social-ecological system. There are numerous suitable methodologies (e.g., Schultz et al., 2007; Reed et al., 2009; Baird et al., 2014), but particular attention should be paid to power relationships amongst stakeholders and communities, which are often overlooked (Armitage et al., 2009; Fabinyi et al., 2014; Butler et al., 2015b; Boonstra, 2016). To understand potential power asymmetries in any rewilding project, it would be essential to analyse the political dynamics, and to ensure that weaker or marginalised stakeholders are adequately represented. Additionally, the most powerful must be willing to share decision-making, rather than dominate it. It may also be necessary to create a steering committee, independent from the facilitation team, which represents the major stakeholder groups to provide the political legitimacy for the governance structure, and to formally link to national policy processes (Butler et al., 2016a,b).

\section{Process}

Our over-arching process is the well-known adaptive management cycle, involving the steps of plan, design, implement, monitor and evaluate, and revise (Williams et al., 2009). We simplify this into three steps (see Figure 1):

Step 1: Plan and design. This applies to the plan and design of the rewilding initiative. There may be legal requirements which pre-determine the format of this activity, particularly where public lands such as national parks are concerned, or locations including First Nation or Aboriginal land rights (Pratt Miles, 2013). Encouraging stakeholders to participate, and understanding their incentives to do so, can be problematic, and contains its own ethical and political tensions (Cooke and Kothari, 2001; Stringer et al., 2006; Hurlbert and Gupta, 2015) which the facilitation team must have skills to manage (Butler et al., 2017). However, fundamental is the creation of a forum that 


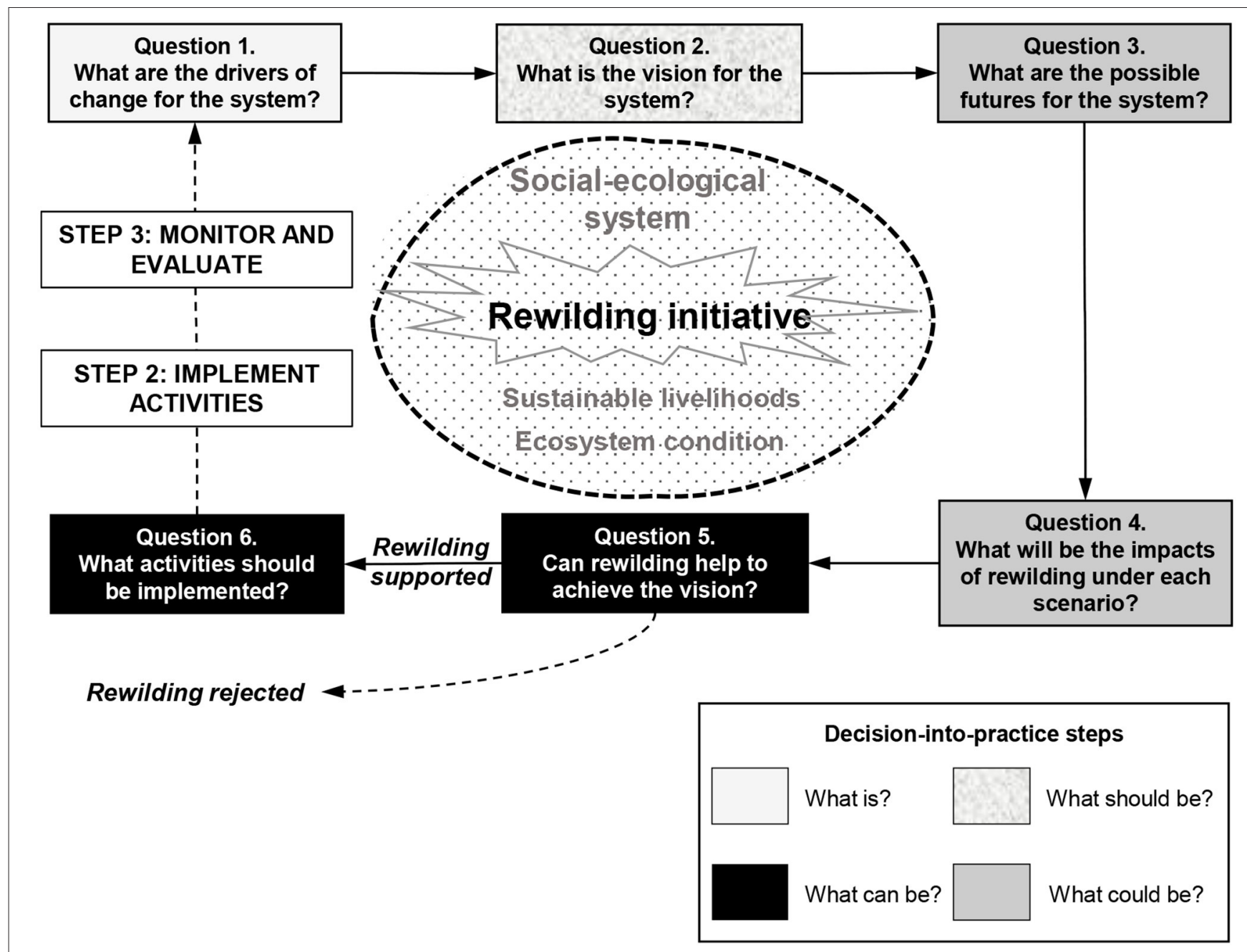

FIGURE 1 | The sequence of questions (1-6) involved in the decision-into-practise exercise proposed for Step 1 (plan and design). If the rewilding initiative is supported after Question 5 then the outcome of Question 6 leads to Step 2 (implement activities) and Step 3 (monitor and evaluate). The process then cycles back into Step 1 and the sequence of questions is repeated in subsequent adaptive management cycles.

can engage stakeholders in open dialogue, and where different knowledge can be considered and respected equally.

Step 1 could be initiated with a multi-stakeholder activity which catalyses social learning and consensus-building. Brown (2008) designed a "decision-into-practice" learning exercise which has been effectively adapted to initiate similar planning processes for community development (Brown and Lambert, 2015) and climate change adaptation (Butler et al., 2015b, 2016c). Referring to the system and issue concerned, four questions are addressed in succession: "what is?" "what should be?" "what could be?" and "what can be?" resulting in an agreed set of actions. In this case the four questions are expanded to six, and the issue is the potential effects of a rewilding initiative within a social-ecological system, and consideration of potential ecosystem and livelihood outcomes (Figure 1).

Question 1 addresses the drivers of change influencing the system, thus establishing the social-ecological context and "what is?" (Figure 1). This deliberately identifies multiple social (e.g., human population trends, livelihood changes) and ecological (e.g., climate change, habitat dynamics) drivers that rewilding will interact with. Question 2 establishes the stakeholders' vision for the system, and hence a consensus on "what should be?" including the role and impact of conservation on material, social and subjective aspects of human wellbeing (De Lange et al., 2016; Woodhouse et al., 2016). Question 3 examines potential future system states given trends and uncertainties in the primary drivers identified in the first question. Scenario planning is an effective and well-established tool for this activity (e.g., OterosRozas et al., 2015; Butler et al., 2020).

The process then casts the rewilding initiative into the system context and stakeholders' agreed vision (Figure 1). Question 4 considers the potential impact of rewilding on each future system state. At this stage various tools and information already established in rewilding and restoration science could be applied, including landscape suitability assessments, prey availability (for carnivores), and current management effectiveness. Based on 
these assessments, Question 5 judges whether the initiative complements or impedes the attainment of the stakeholders' vision, thus asking "what can be?"

If rewilding is compatible with the vision, or requires modification, Question 6 seeks to agree a program of strategies and innovations which can be rolled out in Step 2 (below). At

TABLE 1 | Proposed indicators for evaluating (A) rewilding governance outcomes and (B) pre-conditions for ongoing adaptive governance, showing alignment with ACM and SLO themes, adapted from Butler et al. (2015a).

\section{Indicator}

Governance themes

\section{A. Outcomes \\ 1. New institutional arrangements \\ 2. New institutions formally codified \\ 3. Rewilding management plan \\ 4. Legitimisation of policies and actions \\ 5. Changes in perceptions and actions \\ 6. Engagement and learning across scales \\ 7. Questioning of routines, values and governance \\ 8. Creative ideas for problem-solving \\ 9. Agreed upon sanctions \\ 10. No party asserting its interests to the detriment of others \\ 11. Rewilding outcomes (including social outcomes) acceptable to all parties}

12. Acceptable level of ecosystem function

\section{B. Pre-conditions}

1. Presence of a bridging organisation

or individual

2. Commitment to long-term

institution building

3. Adaptable portfolio of management resources

4. Provision of training and

capacity-building

5. Stakeholders drawing on and

sharing diverse knowledge

6 . Formal and regular evaluation with stakeholders

7. High quality of information and resources

8. Leaders prepared to champion the process

9. Supportive policy environment

10. Transparency of stakeholders' goals and values

11. Trust amongst stakeholders

12. Participation of all impacted stakeholders
New institutions-ACM, SLO

New institutions-ACM, SLO

New institutions-ACM, SLO

New institutions-ACM, SLO

Iterative co-learning-ACM

Cross-scale networks-ACM

Iterative co-learning-ACM

Knowledge generation-ACM

New institutions-ACM, SLO

Power-sharing-ACM, SLO

Power-sharing, sustainable livelihoods-ACM, SLO

Power-sharing, ecosystem condition-ACM, SLO

New institutions-ACM

New institutions-ACM, SLO

Knowledge generation-ACM

Knowledge generation-ACM

Knowledge generation-ACM

Knowledge generation-ACM

Leadership-ACM

Power-sharing-ACM, SLO

Trust and transparency-SLO

Trust and transparency-SLO

Representation-ACM, SLO
Iterative co-learning-ACM this stage, agreement can be reached about identifying potential social risks to monitor, together with their baselines. Whilst such risks will vary according to location and populations, Woodhouse et al. (2016) have developed generic indicators of social risks or outcomes of conservation, which could be used to help identify social components to measure. If rewilding is not compatible with the vision and is therefore not supported, the proposal could be rejected at this point. Importantly, this co-learning process may still galvanise stakeholder action to better govern the existing system toward an agreed vision.

Step 2: Implement activities. Here we refer to the activities identified by Step 1. Fundamental to this is multi-stakeholder engagement in learning-by-doing experiments (Armitage et al., 2009; Plummer, 2009; Plummer et al., 2012). Each may involve a sub-set of actors, and possibly others additional to those identified in Step 1.

Step 3: Monitor and evaluate. This should be engrained within all activities to create a culture of ongoing reflection and learning (Armitage et al., 2009), enabled by the facilitation team and championed by leaders. Different forms of monitoring and evaluation may be applied to different aspects of the initiative. For example, an overall Theory of Change (ToC) could be developed for the rewilding initiative which articulates a vision of change, and systematically describes the sequence of activities, outputs, outcomes and impacts to achieve it, and the assumptions about the relationships between interventions and change (Vogel, 2012; Bours et al., 2013; Maru et al., 2018). If the ToC is carried out in a participatory process which engages stakeholders to reflect and learn, this has the added advantage of catalysing action to improve the ongoing design in subsequent cycles (Butler et al., 2015a, 2016a; Plummer et al., 2017; Trimble and Plummer, 2018; Cox et al., 2020).

Any evaluation should also consider the effectiveness of the governance process and necessary adjustments in terms of ACM and SLO principles. Plummer and Armitage (2007) devised a framework to measure ACM outcomes in terms of sustainable livelihoods and ecosystem condition, plus processes and institutions, that could be expanded to incorporate nonmaterial aspects of human wellbeing. Armitage et al. (2009) identified further pre-conditions for the continuation of effective ACM. These frameworks, and methods for applying them have since been trialled in different natural resource management (e.g., Cundill and Fabricius, 2010), protected area (e.g., Plummer et al., 2017), climate adaptation (e.g., Butler et al., 2016b) and conservation conflict contexts (e.g., Butler et al., 2015a; Cox et al., 2020). The primary outcome sought through SLO is community agreement and acceptance of an initiative, exhibited as degrees of developer-community partnerships, trust, transparency and conflict resolution. While it is recognised that monitoring these outcomes is important (Roche and Bice, 2013), and SLO indicators have been developed for management (e.g., Boutilier et al., 2012; Provasnek et al., 2017; Lindman et al., 2020), their focus has been cost-benefit assessments, and as yet no governance-focussed frameworks exist for evaluating SLO.

Considering the complementarities between ACM and SLO's themes, an indicator framework is suggested which assesses institutional, process, wellbeing, livelihoods and ecosystem

Indicators added specifically for rewilding are italicised. 
outcomes, and pre-conditions for adaptive governance to continue (Table 1). This adapts an approach originally designed for evaluating the ACM of conservation conflict by Butler et al. (2015a). To apply the framework for rewilding, we have refined two outcome indicators: "rewilding management plan" and "rewilding outcomes (including social outcomes) acceptable to all parties" (Table 1). Tools such as community surveys, which are often applied for SLO (Roche and Bice, 2013) could be applied to assess the latter. To evaluate conflict transformation, which capitalises on the identification of the root socio-political sources of conflict, the outcome indicator "questioning of routines, values and governance" could examine stakeholders' underlying perceptions of the drivers of conflict, and whether the process has succeeded in altering them.

\section{DISCUSSION}

Rewilding is emerging as a pragmatic approach to repairing damaged ecosystems, yet guidelines for its governance remain relatively immature. Despite the critical importance of stakeholder engagement, adaptive experimentation and learning, the landmark IUCN/SSC guidelines (IUCN/SSC, 2013) only advise proponents to consider community perceptions, costs, and benefits. They do not incorporate adaptive governance approaches that are tailored to the social-ecological reverberations that rewilding is likely to induce. We have attempted to address this gap by proposing a governance approach based on contemporary principles of ACM and SLO. We hope to have broadened the focus of rewilding from a discussion tightly focused on conservation biology and conservation objectives to include social-ecological systems thinking, including human wellbeing, sustainable livelihoods, and ecosystem condition outcomes. We would argue that whilst this may add extra layers onto a rewilding initiative, the risks of not incorporating these social dimensions at the outset could result in rewilding initiatives becoming hampered by long-term and acute conflicts, with negative impacts on biodiversity and human wellbeing.

We believe that our approach is sufficiently generic to be applicable across the diversity of contexts in which rewilding is being considered. Since both ACM and SLO are themselves evolving, and have not yet been applied to rewilding, there is no blueprint for their application. Armitage et al. (2009) suggested that where resource use is poorly defined or distributed over large geographical areas with a plethora of stakeholders, and hence high transactional costs, ACM may be less effective. This has been experienced in the UK (Butler et al., 2008; Young et al., 2010) and may limit the utility of our framework in some contexts. Consequently, our proposed structure and process is not prescriptive, and deliberately only offers a skeleton to be tested. Not all elements need to be addressed in-depth in all rewilding initiativesindeed, our intention with this framework is not to drain stakeholder energy from the rewilding activity, but rather to pre-empt and manage potential conflicts that might hamper the effectiveness of initiatives. As such, the indicator framework proposed in Table 1 for monitoring and evaluating rewilding outcomes and pre-conditions for ongoing adaptive governance contains the key themes of our approach, which should be maintained if possible. Trials of the approach would iteratively inform future initiatives and streamline its structure and process.

A review of rewilding case studies indicates that some rewilding initiatives are evolving adaptive governance (Butler et al., 2019). We suggest, however, that our approach should be engineered in advance, as has been achieved for ACM in some cases (Cundill and Fabricius, 2010; Smedstad and Gosnell, 2013; Butler et al., 2016a,b). This could avoid significant transaction costs in controversial initiatives, where stakeholder conflict may otherwise escalate. In less contentious cases, our approach would still promote transparent governance and adaptive capacity and enable stakeholders to attain livelihood and ecosystem outcomes while accounting for future uncertainties. Even if during Step 1 (plan and design) a rewilding proposal is not supported, the process may still catalyse improved stewardship of the social-ecological system concerned. Whatever the approach, to be effective any adaptive governance process requires adequate and sustained resourcing, including support for bridging organisations or individuals.

In conclusion, we suggest that the proposed adaptive governance framework can accommodate the emergent uncertainties and conflicts characteristic of a social-ecological system that is altered by rewilding. We thus call on decisionmakers and practitioners to test our suggested structure and process, including the application of our evaluation indicators.

\section{DATA AVAILABILITY STATEMENT}

The original contributions presented in the study are included in the article/supplementary material, further inquiries can be directed to the corresponding author.

\section{AUTHOR CONTRIBUTIONS}

JRAB, MM, NP, SMD, JTT, and JCY all contributed to the development of the concepts presented in the paper. JRAB led on the writing, supported by MM, NP, SMD, JTT, and JCY. All authors contributed to the article and approved the submitted version.

\section{FUNDING}

SMD and NP were supported by Research England. SMD was also funded by the Howard G. Buffett Foundation through the African Range-Wide Cheetah Conservation Initiative.

\section{ACKNOWLEDGMENTS}

We would like to thank two reviewers for their constructive comments on previous draughts of this manuscript. 


\section{REFERENCES}

Armitage, D. R., Plummer, R., Berkes, F., Arthur, I. R., Charles, A. T., Diduck, A. P., et al. (2009). Adaptive co-management for social-ecological complexity. Front. Ecol. Environ. 7, 95-102. doi: 10.1890/070089

Baird, J., Plummer, R., and Pickering, K. (2014). Priming the governance system for climate change adaptation: the application of a socialecological inventory to engage actors in Niagara, Canada. Ecol. Soc. 19:3. doi: 10.5751/ES-06152-190103

Batson, W. G., Gordon, I. J., Fletcher, D. B., and Manning, A. D. (2015). Translocation tactics: a framework to support the IUCN guidelines for wildlife translocations and improve the quality of applied methods. J. Appl. Ecol. 52, 1598-1607. doi: 10.1111/1365-2664.12498

Bellanger, M., Speir, C., Blanchard, F., Brooks, K., Butler, J. R. A., Crosson, S., et al. (2020). Addressing marine and coastal governance conflicts at the interface of multiple sectors and jurisdictions. Front. Mar. Sci. 7:544440. doi: $10.3389 /$ fmars.2020.544440

Berkes, F. (2009). Community conserved areas: policy issues in historic and contemporary context. Conserv. Lett. 2, 19-24. doi: 10.1111/j.1755-263X.2008.00040.x

Boonstra, W. J. (2016). Conceptualizing power to study social-ecological interactions. Ecol. Soc. 21:21. doi: 10.5751/ES-07966-210121

Bours, D., McGinn, C., and Pringle, P. (2013). Monitoring and Evaluation for Climate Change Adaptation: A Synthesis of Tools, Frameworks and Approaches. Oxford: SEA Change CoP, Phnom Penh and UKCIP.

Boutilier, R. G., Black, L., and Thomson, I. (2012). "From metaphor to management tool: how the social license to operate can stabilise the sociopolitical environment for business," in International Mine Management 2012 Proceedings (Melbourne, VIC), 227-237.

Brown, V. A. (2008). Leonardo's Vision: A Guide to Collective Thinking and Action. Rotterdam: Sense Publishers.

Brown, V. A., and Lambert, J. A. (2015). Transformational learning: are we all playing the same "game"? J. Trans. Learn. 3, 35-41. Available online at: https:// jotl.uco.edu/index.php/jotl/article/view/49/47

Butler, J. R. A., Bergseng, A.-M., Bohensky, E. L., Aitkenhead, M., Pedde, S., and Hamden, R. (2020). Adapting scenarios for climate adaptation: practitioners' perspectives on a popular planning method. Environ. Sci. Policy 104, 13-19. doi: 10.1016/j.envsci.2019.10.014

Butler, J. R. A., Bohensky, E. L., Darbas, T., Kirono, D. G. C., Wise, R. M., and Sutaryono, Y. (2016a). Building capacity for adaptation pathways in eastern Indonesian islands: synthesis and lessons learned. Clim. Risk Manag. 12, A1A10. doi: 10.1016/j.crm.2016.05.002

Butler, J. R. A., Bohensky, E. L., Suadnya, W., Yanuartati, Y., Handayani, T., Habibi, P., et al. (2016c). Scenario planning to leap-frog the sustainable development goals: an adaptation pathways approach. Clim. Risk Manag. 12, 83-99. doi: 10.1016/j.crm.2015.11.003

Butler, J. R. A., Darbas, T., Addison, J., Bohensky, E. L., Carter, L., Cosijn, M., et al. (2017). "A hierarchy of needs for achieving impact in international research for development projects," in Social Science and Sustainability, eds H. Schandl and I. Walker (Clayton, VIC: CSIRO Publishing), 109-129.

Butler, J. R. A., Middlemas, S. J., McKelvey, S. A., McMyn, I., Leyshon, B., Walker, I., et al. (2008). The moray firth seal management plan: an adaptive framework for balancing the conservation of seals, salmon, fisheries, and wildlife tourism in the UK. Aquat. Conserv. Mar. Freshw. Ecosyst. 18, 1025-1038. doi: 10.1002/aqc.923

Butler, J. R. A., Suadnya, I. W., Yanuartati, Y., Meharg, S., Wise, R. M., Sutaryono, Y., et al. (2016b). Priming adaptation pathways through adaptive co-management: design and evaluation for developing countries. Clim. Risk Manag. 12, 1-16. doi: 10.1016/j.crm.2016.01.001

Butler, J. R. A., Tawake, L., Tawake, A., Skewes, T., and McGrath, V. (2012). Integrating traditional ecological knowledge and fisheries management in the Torres Strait, Australia: the catalytic role of turtles and dugong as cultural keystone species. Ecol. Soc. 17:34. doi: 10.5751/ES-05165-170434

Butler, J. R. A., Wise, R. M., Skewes, T. D., Bohensky, E. L., Peterson, N., Suadnya, W., et al. (2015b). Integrating top-down and bottom-up adaptation planning to build adaptive capacity: a structured learning approach. Coast. Manag. 43, 346-364. doi: 10.1080/08920753.2015.1046802
Butler, J. R. A., Young, J. C., and Marzano, M. (2019). “Adaptive governance and conflict resolution for rewilding across development contexts," in Rewilding, eds N. Pettorelli, S. Durant, and J. T. du Toit (Cambridge: British Ecological Society and Cambridge University Press), 386-412. doi: 10.1017/9781108560962.019

Butler, J. R. A., Young, J. C., McMyn, I., Leyshon, B., Graham, I. M., Walker, I., et al. (2015a). Evaluating adaptive co-management as conservation conflict resolution: learning from seals and salmon. J. Environ. Manage. 160, 212-225. doi: 10.1016/j.jenvman.2015.06.019

Campese, J., Nakangu, B., Silverman, A., and Springer, J. (2016). The Natural Resource Governance Framework Assessment Guide: Learning for Improved Natural Resource Governance. NRGF Paper. Gland: IUCN and CEESP.

Cooke, B., and Kothari, U. (2001). Participation: The New Tyranny. London: Zed Press.

Corlett, R. T. (2016). Restoration, reintroduction, and rewilding in a changing world. Trends Ecol. Evol. 31, 453-462. doi: 10.1016/j.tree.2016.02.017

Cox, T., Butler, J. R. A., Webber, A., and Young, J. C. (2020). The ebb and flow of adaptive co-management: a longitudinal evaluation of a conservation conflict. Environ. Sci. Policy 114, 453-460. doi: 10.1016/j.envsci.2020.09.017

Coz, D. M., and Young, J. C. (2020). Conflicts over wildlife conservation: learning from the reintroduction of beavers in Scotland. People Nat. 2, 406-419. doi: $10.1002 /$ pan3.10076

Cundill, G., and Fabricius, C. (2010). Monitoring the governance dimension of natural resource co-management. Ecol. Soci. 15:15. doi: 10.5751/ES-03346-150115

De Lange, E., Woodhouse, E., and Milner-Gulland, E. J. (2016). Evaluating the impacts of conservation interventions on human well-being: guidance for practitioners. Oryx 5101, 14-15. doi: 10.1017/S0030605316001423

Drouilly, M., and O'Riain, M. J. (2021). Rewilding the world's large carnivores without neglecting the human dimension. Biodivers. Conserv. 30, 917-923. doi: 10.1007/s10531-021-02112-y

Durant, S., Pettorelli, N., and du Toit, J. T. (2019). "The future of rewilding: fostering nature and people in a changing world," in Rewilding, eds N. Pettorelli, S. Durant, and J. T. du Toit, J.T. (Cambridge: British Ecological Society and Cambridge University Press), 413-425.

Fabinyi, M., Evans, L., and Foale, S. J. (2014). Social-ecological systems, social diversity, and power: insights from anthropology and political ecology. Ecol. Soc. 19:28. doi: 10.5751/ES-07029-190428

Fabricius, C., and Cundill, G. (2014). Learning in adaptive management: insights from published practice. Ecol. Soc. 19:29. doi: 10.5751/ES-06263-190129

Folke, C., Carpenter, S., Elmqvist, T., Gunderson, L., Holling, C. S., Walker, B., et al. (2002). "Resilience and sustainable development: building adaptive capacity in a world of transformations," in The Environmental Advisory Council to the Swedish Government Scientific Background Paper (Stockholm).

Folke, C., Hahn, T., Olsson, P., and Norberg, J. (2005). Adaptive governance of social-ecological systems. Ann. Rev. Environ. Resour. 30, 441-473. doi: 10.1146/annurev.energy.30.050504.144511

Ford, R. M., and Williams, K. J. H. (2016). How can social acceptability research in Australian forests inform social licence to operate? Forestry 89, 512-524. doi: 10.1093/forestry/cpv051

Gallopin, G. C. (1991). Human dimensions of global change: linking the global and the local processes. Int. Soc. Sci. J. 130, 707-718.

Hurlbert, M., and Gupta, J. (2015). The split ladder of participation: a diagnostic, strategic, and evaluation tool to assess when participation is necessary. Environ. Sci. Policy 50, 100-113. doi: 10.1016/j.envsci.2015.01.011

IUCN (2021). Available online at: https://www.iucncongress2020.org/motion/100 (accessed April 24, 2021).

IUCN/SSC (2013). Guidelines for Reintroductions and Other Conservation Translocations. Version 1.0. Gland: IUCN Species Survival Commission.

Keith, D. A., Martin, T. G., McDonald-Madden, E., and Walters, C. (2011). Uncertainty and adaptive management for biodiversity conservation. Biol. Conserv. 144, 1175-1178. doi: 10.1016/j.biocon.2010. 11.022

Kendal, D., and Ford, R. M. (2017). The role of social license in conservation. Conserv. Biol. 32, 493-495. doi: 10.1111/cobi.12994

Lacey, J., and Lamont, J. (2014). Using social contract to inform social licence to operate: an application in the Australian coal seam gas industry. J. Clean. Prod. 84, 831-839. doi: 10.1016/j.jclepro.2013.11.047 
Lindman, Å., Ranängen, H., and Kauppila, O. (2020). Guiding corporate social responsibility practice for social license to operate: a Nordic mining perspective. Extr. Ind. Soc. 7, 892-907. doi: 10.1016/j.exis.2020.07.013

Maru, Y. T., Sparrow, A., Butler, J. R. A., Banerjee, O., Ison, R., Hall, A., et al. (2018). Towards appropriate mainstreaming of "Theory of Change" approaches into agricultural research for development: challenges and opportunities. Agric. Syst. 165, 344-353. doi: 10.1016/j.agsy.2018.04.010

Moffat, K., Lacey, J., Zhang, A., and Leipold, S. (2016). The social licence to operate: a critical review. Forestry 89, 477-488. doi: 10.1093/forestry/cpv044

Nogués-Bravo, D., Simberloff, D., Rahbek, C., and Sanders, N. J. (2016). Rewilding is the new Pandora's box in conservation. Curr. Biol. 26, R83-R101. doi: $10.1016 /$ j.cub.2015.12.044

Ojha, H. R., Ford, R., Keenan, R. J., Race, D., Carias Vega, D., Baral, H., et al. (2016). Delocalizing communities: changing forms of community engagement in natural resources governance. World Dev. 87, 274-290. doi: 10.1016/j.worlddev.2016.06.017

Olsson, P., Folke, C., and Berkes, F. (2004). Adaptive co-management for building resilience in social-ecological systems. Environ. Manage. 34, 75-90. doi: 10.1007/s00267-003-0101-7

Olsson, P., Gunderson, L. H., Carpenter, S. R., Ryan, P., Lebel, L., Folke, C., et al. (2006). Shooting the rapids: navigating transitions to adaptive governance of social-ecological systems. Ecol. Soc. 11:18. doi: 10.5751/ES-01595-110118

Oteros-Rozas, E., Martín-López, B., Daw, T., Bohensky, E., Butler, J. R. A., Hill, R., et al. (2015). Participatory scenario-planning in place-based social-ecological research: insights and experiences from 23 case studies. Ecol. Soc. 20:32. doi: 10.5751/ES-07985-200432

Pettorelli, N., Barlow, J., Stephens, P. A., Durant, S. M., Connor, B., Bühne, H. S., et al. (2018). Making rewilding fit for policy. J. Appl. Ecol. 55, 1114-1125. doi: $10.1111 / 1365-2664.13082$

Pettorelli, N., Durant, S., and du Toit, J. T. (2019). "Rewilding: a captivating, controversial, twenty-first-century concept to address ecological degradation in a changing world," in Rewilding, eds N. Pettorelli, S. Durant, and J. T. du Toit (Cambridge: British Ecological Society and Cambridge University Press), 1-11.

Plummer, R. (2009). The adaptive co-management process: an initial synthesis of representative models and influential variables. Ecol. Soc. 14:24. doi: 10.5751/ES-03130-140224

Plummer, R., and Armitage, D. (2007). A resilience-based framework for evaluating adaptive co-management: linking ecology, economics and society in a complex world. Ecol. Econ. 61, 62-74. doi: 10.1016/j.ecolecon.2006.09.025

Plummer, R., Baird, J., Dzyundzyak, A., Armitage, D., Bodin, O., and Schultz, L. (2017). Is adaptive co-management delivering? Examining relationships between collaboration, learning and outcomes in UNESCO Biosphere Reserves. Ecol. Econ. 140, 79-88. doi: 10.1016/j.ecolecon.2017.04.028

Plummer, R., Crona, B., Armitage, D. R., Olsson, P., Tengö, M., and Yudina, O. (2012). Adaptive co-management: a systematic review and analysis. Ecol. Soc. 17:11. doi: $10.5751 /$ ES-04952-170311

Pratt Miles, J. D. (2013). Designing collaborative processes for adaptive management: four structures for multi-stakeholder collaboration. Ecol. Soc. 18:5. doi: 10.5751/ES-05709-180405

Provasnek, A. K., Sentic, A., and Schmid, E. (2017). Integrating eco-innovations and stakeholder engagement for sustainable development and a social license to operate. Corp. Soc. Responsib. Environ. Manag. 24, 173-185. doi: $10.1002 /$ csr. 1406

Redpath, S., Linnell, J., Festa-Bianchet, M., Boitani, L., Bunnefeld, N., Dickman, A., et al. (2017). Don't forget to look down-collaborative approaches to predator conservation. Biol. Rev. 92, 2157-2163. doi: 10.1111/brv.12326

Redpath, S., Young, J., Evely, A., Adams, W. M., Sutherland, W. J., Whitehouse, A., et al. (2013). Understanding and managing conflicts in biodiversity conservation. Trends Ecol. Evol. 28, 100-109. doi: 10.1016/j.tree.2012.08.021

Reed, M. S., Graves, A., Dandy, N., Posthumus, H., Hubacek, K., Morris, J., et al. (2009). Who's in and why? a typology of stakeholder analysis methods for natural resource management. J. Environ. Manag. 90, 1933-1949. doi: 10.1016/j.jenvman.2009.01.001
Rist, L., Felton, A., Samuelsson, L., Sandstrom, C., and Rosvall, O. (2013). A new paradigm for adaptive management. Ecol. Soc. 18:63. doi: 10.5751/ES-06183-180463

Robert, A., Colas, B., Guigon, I., Kerbiriou, C., Mihoub, J. B., Saint-Jalme, M., et al. (2015). Defining reintroduction success using IUCN criteria for threatened species: a demographic assessment. Anim. Conserv. 18, 397-406. doi: $10.1111 /$ acv. 12188

Roche, C., and Bice, S. (2013). "Anticipating social and community impacts of deep sea mining," in Deep Sea Minerals: Deep Sea Minerals and the Green Economy, Vol. 2, eds E. Baker and Y. Beaudoin (Suva: Secretariat of the Pacific Community), 59-80.

Schultz, L., Folke, C., and Olsson, P. (2007). Enhancing ecosystem management through social-ecological inventories. Lessons learned from Kristianstads Vattenrike Biosphere Reserve. Environ. Conserv. 34, 140-152. doi: 10.1017/S03768929070 03876

Skrimizea, E., Lecuyer, L., Bunnefeld, N., Butler, J. R. A., Fickel, T., Hodgson, I., et al. (2020). Sustainable agriculture: recognizing conflict as a positive driver for transformative change. Adv. Ecol. Res. 63, 255-311. doi: 10.1016/bs.aecr.2020.08.003

Smedstad, J. A., and Gosnell, H. (2013). Do adaptive co-management processes lead to adaptive co-management outcomes? a multi-case study of longterm outcomes associated with the National Riparian Service Team's place-based riparian assistance. Ecol. Soc. 18:8. doi: 10.5751/ES-05793-1 80408

Stringer, L. C., Dougill, A. J., Fraser, E., Hubacek, K., Prell, C., and Reed, M. S. (2006). Unpacking "participation" in the adaptive management of socialecological systems: a critical review. Ecol. Soc. 11:39. doi: 10.5751/ES-01896-1 10239

Trimble, M., and Plummer, R. (2018). Participatory evaluation for adaptive co-management of social-ecological systems: a transdisciplinary research approach. Sustain. Sci. 14, 1091-1103. doi: 10.1007/s11625-0180602-1

Vogel, I. (2012). Review of the Use of "Theory of Change" in International Development. UK Department for International Development.

Williams, B. K., Szaro, R. C., and Shapiro, C. D. (2009). Adaptive Management: The US Department of the Interior Technical Guide. Washington, DC: US Department of the Interior.

Woodhouse, E., de Lange, E., and Milner-Gulland, E. J. (2016). Evaluating the Impacts of Conservation Interventions on Human Wellbeing. London: Guidance for Practitioners. IIED.

Young, J., Butler, J. R. A., Jordan, A., and Watt, A. D. (2012). Less government intervention in biodiversity management: Risks and opportunities. Biodivers. Conserv. 21, 1095-1100. doi: 10.1007/s10531-012-0243-0

Young, J. C., Marzano, M., White, R. M., McCracken, D. I., Redpath, S. M., Carss, D. N., et al. (2010). The emergence of biodiversity conflicts from biodiversity impacts: characteristics and management strategies. Biodivers. Conserv. 19, 3973-3990. doi: 10.1007/s10531-010-9941-7

Young, J. C., Thompson, D., Moore, P., MacGugan, A., Watt, A. D., and Redpath, S. M. (2016). A conflict management tool for conservation agencies. J. Appl. Ecol. 53, 705-711. doi: 10.1111/1365-2664.12612

Conflict of Interest: The authors declare that the research was conducted in the absence of any commercial or financial relationships that could be construed as a potential conflict of interest.

Copyright $(02021$ Butler, Marzano, Pettorelli, Durant, du Toit and Young. This is an open-access article distributed under the terms of the Creative Commons Attribution License (CC BY). The use, distribution or reproduction in other forums is permitted, provided the original author(s) and the copyright owner(s) are credited and that the original publication in this journal is cited, in accordance with accepted academic practice. No use, distribution or reproduction is permitted which does not comply with these terms. 